\title{
Successful resuscitation from prolonged hypothermic cardiac arrest without extracorporeal life support: a case report
}

\author{
Melanie Kuhnke ${ }^{1,2^{*}}$, Roland Albrecht ${ }^{1}$, Joerg C. Schefold ${ }^{2}$ and Peter Paal ${ }^{3}$
}

\begin{abstract}
Background: We report a case of successful prolonged cardiopulmonary resuscitation (5 hours and 44 minutes) following severe accidental hypothermia with cardiac arrest treated without rewarming on extracorporeal life support.

Case presentation: A 52-year-old Italian mountaineer, was trapped in a crevasse and rescued approximately 7 hours later by a professional rescue team. After extrication, he suffered a witnessed cardiac arrest with ventricular fibrillation. Immediate defibrillation and cardiopulmonary resuscitation were started. His core temperature was $26.0^{\circ} \mathrm{C}$. Due to weather conditions, air transport to an extracorporeal life support center was not possible. Thus, he was rewarmed with conventional rewarming methods in a rural hospital. Auto-defibrillation occurred at a core temperature of $29.8^{\circ} \mathrm{C}$ after 5 hours and 44 minutes of continued cardiopulmonary resuscitation. With a core temperature of $33.4^{\circ} \mathrm{C}$, he was finally admitted to a level 1 trauma center and extracorporeal life support was no longer required. Seven weeks following the accident, he was discharged home with complete neurological recovery.

Conclusions: Successful rewarming from severe hypothermia without extracorporeal life support use as performed in this case suggests that patients with primary hypothermic cardiac arrest have a chance of a favorable neurological outcome even after several hours of cardiac arrest when cardiopulmonary resuscitation and conventional rewarming are performed continuously. This may be especially relevant in remote areas, where extracorporeal life support rewarming is not available.
\end{abstract}

Keywords: Hypothermia, Cardiac arrest, Cardiopulmonary resuscitation, ECLS, Mechanical CPR

\section{Background}

Cardiac arrest from severe accidental hypothermia is a rare event. The clinical outcome may be favorable if patients are resuscitated in time and rewarmed until return of spontaneous circulation (ROSC) [1]. During the past two decades, extracorporeal life support (ECLS) rewarming has become a cornerstone in the treatment of patients with hypothermia-induced cardiac arrest [2, 3]. We report the case of a patient in whom ECLS rewarming was not possible due to bad weather impeding transport to an ECLS center. Cardiopulmonary resuscitation (CPR)

\footnotetext{
* Correspondence: melaniekuhnke@gmx.net; melanie.kuhnke@rega.ch ${ }^{1}$ Swiss Air Rescue, Swiss Air-Ambulance (Rega), P.O. Box 1414, 8058 Zurich, Switzerland

2Department of Intensive Care Medicine, Inselspital, Bern University Hospital, University of Bern, Bern, Switzerland

Full list of author information is available at the end of the article
}

was performed for 5 hours and 44 minutes and the patient rewarmed with warm forced air, warm blankets, and warm infusions only. Auto-defibrillation occurred. After 20 days in an intensive care unit and 7 weeks in hospital, the patient was discharged neurologically intact.

\section{Case presentation}

A 52-year-old lightly dressed Italian mountaineer was hiking alone on an Italian glacier at $3085 \mathrm{~m}$, when he fell about $15 \mathrm{~m}$ into a crevasse at approximately 14:00 (Fig. 1). Ice-water was pouring over him, but he was able to breathe. His wife alerted a rescue team to report him missing. After over 7 hours in the crevasse, he was found and rescued at 21:40. He complained about being cold but was in no pain. Then he lost consciousness. Night had fallen and low clouds prevented a helicopter rescue. Thus, extraction using terrestrial mountain rescue with a 


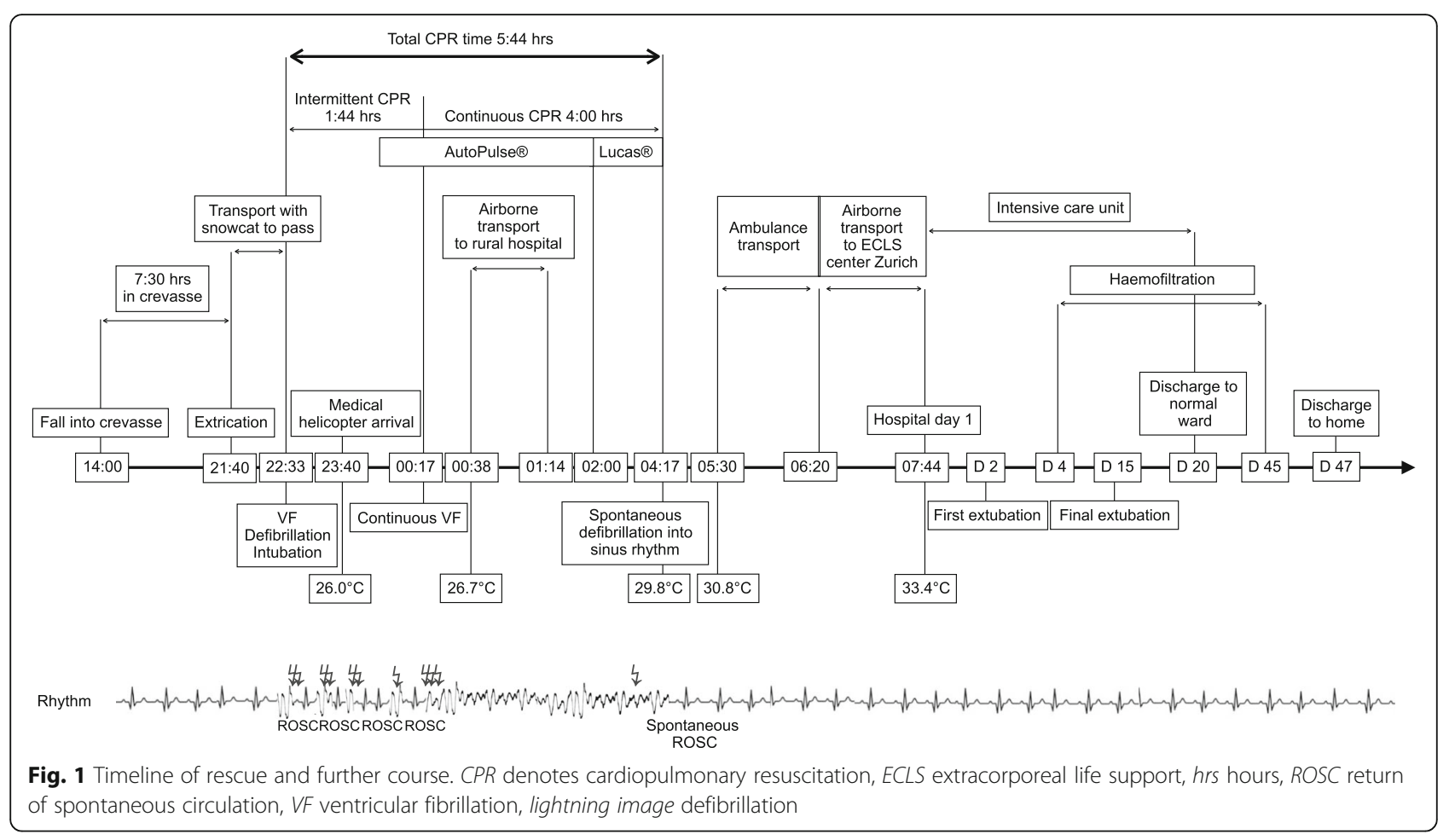

snowcat was commenced. He remained unconscious but was spontaneously breathing; oxygen saturation was $84 \%$ with $2 \mathrm{~L}$ oxygen/minute through a face mask at a heart rate of $60 /$ minute. His trachea was not intubated at this stage because the mountain rescuers on site were only basic life support certified.

At 22:33, after arrival at a mountain pass at $2750 \mathrm{~m}$, he developed ventricular fibrillation (VF), which initially responded to immediate defibrillation, but then recurred. ROSC was achieved two more times with a total of six defibrillations; his blood pressure was 120/70 mmHg. During resuscitation, he was intubated. A Swiss rescue helicopter with night-flying capability was requested to transport the patient directly to an ECLS rewarming center. When the helicopter arrived at 23:40, his esophageal temperature was $26.0^{\circ} \mathrm{C}$. An electrical warming blanket (Geratherm ${ }^{\circ}$ UniqueResc+, Geratherm Medical AG, Geschwenda, Germany) was placed on his abdomen, and a mechanical chest compression device was placed in case of VF recurrence.

Soon after, VF recurred and was terminated with one defibrillation, but after a few minutes, VF recurred again. Three further defibrillation attempts remained unsuccessful; thus, continuous CPR with mechanical chest compression (AutoPulse ${ }^{\circ}$, Zoll Medical, Cologne, Germany) was started, further defibrillation attempts were considered obsolete at a core temperature of $26.0^{\circ} \mathrm{C}$ [3]. Weather conditions again precluded transport to the ECLS center and he was air transferred to the closest rural hospital. An arterial blood gas analysis showed a $\mathrm{pH}$ of 7.2 , lactate $11.2 \mathrm{mmol} /$ $\mathrm{L}$, partial pressure of oxygen in arterial blood $\left(\mathrm{paO}_{2}\right) 18.1$ $\mathrm{kPa}$, and potassium $2.7 \mathrm{mmol} / \mathrm{L}$. This encouraged the team to continue CPR and conventional rewarming, and to push for either transport of the patient to an ECLS center or for a portable ECLS device to be transferred to the patient. In the meantime, the mechanical chest compression device was exchanged with a LUCAS ${ }^{\bullet}$, because it featured a plug-in power supply $\left(\mathrm{LUCAS}^{\circ}\right.$, Jolife AB, Physio Control, Lund Sweden). Conventional rewarming was performed with forced warm air (Bair Hugger ${ }^{\circ}, 3$ M, St. Paul, $\mathrm{MN}$, USA) over his abdomen and inferior extremities and intravenously with warmed normal saline. Warm cotton blankets were placed on his chest around the LUCAS ${ }^{\circ}$ device and over his head and changed every 15-30 minutes. The net rewarming rate was $0.7^{\circ} \mathrm{C} /$ hour.

After a total of 5 hours and 44 minutes of CPR with 4 hours of mechanical CPR and at a core temperature of $29.8^{\circ} \mathrm{C}$, conversion into sinus rhythm occurred spontaneously with sustained ROSC. Finally, at 5:30 a.m., transport by terrestrial ambulance was undertaken across a mountain pass. At 6:20 a.m., weather conditions allowed transport by air to the nearest ECLS center (Zurich, Switzerland). On arrival, his core temperature was $33.4^{\circ} \mathrm{C}$, sinus rhythm. By then, ECLS rewarming was no longer required.

On the second day after admission to the ECLS center, he was awake with a Glasgow Coma Scale of 15. Respiratory and renal failure required mechanical ventilation 
and continuous hemofiltration, followed by intermittent dialysis with good recovery of renal function. He was ventilated for 12 days, extubated on day 15 and discharged from the intensive care unit at day 20. Seven weeks after the accident, he was discharged home from rehabilitation with complete neurological recovery despite a persisting neuropathy in his feet and hands. Four months after the accident, he resumed his job.

\section{Discussion}

Several cases of hypothermic cardiac arrest with successful CPR and favorable neurological outcome were previously reported [2, 3]. However, this case seems remarkable for many reasons. First, this is the longest documented case of CPR with survival after hypothermic cardiac arrest and successful rewarming without ECLS, pleural lavage or peritoneal lavage $[4,5]$. In addition, this is one of the longest cases of successful CPR (5 hours and 44 minutes), 4 hours of which were performed using a mechanical CPR device [6]. Second, in the past two decades, successful resuscitation with non-ECLS rewarming has become less common as ECLS rewarming is encouraged in current resuscitation guidelines $[3,7,8]$ following a landmark study [2]. This case confirms, however, that successful rewarming of cardiac arrest from severe hypothermia is possible by non-ECLS means in cases in which a functioning rescue chain with a dedicated team and continuous CPR are provided. Oxygen demand decreases $6-7 \%$ per $1{ }^{\circ} \mathrm{C}$ of cooling $[9,10]$. In normothermia, CPR states with such durations are not survivable without neurological damage.

For patients with a core temperature $<30^{\circ} \mathrm{C}$ with persistent VF, the advanced cardiovascular life support (ACLS) algorithm of the American Heart Association states that it may be reasonable to perform further defibrillations and administer vasopressors (class IIb) [11]. In contrast, the European Resuscitation Council Guidelines recommend a maximum of three defibrillations and no vasopressors [8]. This discrepancy can be explained by the different interpretation of mainly animal data which show that vasopressors increase the chances of successful defibrillation $<30^{\circ} \mathrm{C}$ but ROSC is not stable and tends to degrade into VF again.

If a patient remains asystolic after rewarming, death most likely occurred (for example caused by asphyxia) before the onset of hypothermic cardiac arrest [3]. Moreover, in hypothermic cardiac arrest, a serum potassium $>12 \mathrm{mmol} / \mathrm{L}$ indicates a low probability of good outcome and discontinuation of CPR should be considered $[3,11]$. In accidentally hypothermic patients in cardiac arrest, serum potassium is a prognostic marker [12-14].

In this case the principles of both Advanced Life Support (ALS) and Advanced Trauma Life Support (ATLS) guidelines were applied.

\section{Conclusions}

In conclusion, we report a case of successful non-ECLSbased rewarming of a patient with witnessed primary hypothermic cardiac arrest with complete neurological recovery. Extensive CPR was provided making this case one of the longest cases of CPR in the literature that resulted in a favorable neurological outcome. In patients with primary hypothermic cardiac arrest, successful rewarming can thus also be achieved with continuous CPR being provided in the absence of ECLS systems. This case should encourage medical teams in their efforts in providing continuous $\mathrm{CPR}$ in primary hypothermic patients even without available ECLS.

\section{Abbreviations \\ CPR: Cardiopulmonary resuscitation; ECLS: Extracorporeal life support; ROSC: Return of spontaneous circulation; VF: Ventricular fibrillation}

\section{Acknowledgements}

We thank Les Gordon MD and Lorenz Theiler MD for critical discussion of the content and revision of the manuscript and Karl Philipp Bühler MD for providing in-hospital data. A special thanks to the Swiss Air Rescue-team, the local rescuers and all contributors of the rescue chain.

\section{Authors' contributions}

MK was the physician on board the helicopter and drafted and revised the manuscript. RA, JCS, and PP edited and revised the manuscript. All four authors participated in the writing of this case report and approved the final manuscript.

\section{Funding}

Not applicable.

\section{Availability of data and materials}

The datasets analyzed in the case report are available from the corresponding author on request.

Ethics approval and consent to participate

Not applicable.

\section{Consent for publication}

Written informed consent was obtained from the patient for the publication of this case report and any accompanying images. A copy of the written consent is available for review by the Editor-in-Chief of this journal.

\section{Competing interests}

The authors declare that they have no competing interests.

\section{Author details}

${ }^{1}$ Swiss Air Rescue, Swiss Air-Ambulance (Rega), P.O. Box 1414, 8058 Zurich, Switzerland. ${ }^{2}$ Department of Intensive Care Medicine, Inselspital, Bern University Hospital, University of Bern, Bern, Switzerland. ${ }^{3}$ Department of Anesthesiology and Intensive Care Medicine, Hospitallers Brothers Hospital, Paracelsus Medical University, Salzburg, Austria.

Received: 17 June 2019 Accepted: 9 October 2019

Published online: 02 December 2019

\section{References}

1. Gordon L, Ellerton JA, Paal P, Peek GJ, Barker J. Severe accidental hypothermia. BMJ. 2014;348:g1675.

2. Walpoth BH, Walpoth-Aslan BN, Mattle HP, Radanov BP, Schroth G, Schaeffler $L$, et al. Outcome of survivors of accidental deep hypothermia and circulatory arrest treated with extracorporeal blood warming. N Engl J Med. 1997;337(21):1500-5.

3. Paal P, Gordon L, Strapazzon G, Brodmann Maeder M, Putzer G, Walpoth B, et al. Accidental hypothermia-an update: The content of 
this review is endorsed by the International Commission for Mountain Emergency Medicine (ICAR MEDCOM). Scand J Trauma Resusc Emerg Med. 2016;24(1):111.

4. Piacentini A, Volonte M, Rigamonti M, Guastella E, Landriscina M. Successful Prolonged Mechanical CPR in a Severely Poisoned Hypothermic Patient: A Case Report. Case Rep Emerg Med. 2012;2012:381798.

5. Gruber E, Beikircher W, Pizzinini R, Marsoner H, Pornbacher M, Brugger $H$, et al. Non-extracorporeal rewarming at a rate of 6.8 degrees $C$ per hour in a deeply hypothermic arrested patient. Resuscitation. 2014;85(8):e119-20.

6. Lexow K. Severe accidental hypothermia: survival after 6 hours 30 minutes of cardiopulmonary resuscitation. Arctic Med Res. 1991;50(Suppl 6):112-4.

7. Brown DJ, Brugger H, Boyd J, Paal P. Accidental hypothermia. N Engl J Med. 2012:367(20):1930-8.

8. Truhlar A, Deakin CD, Soar J, Khalifa GE, Alfonzo A, Bierens JJ, et al. European Resuscitation Council Guidelines for Resuscitation 2015: Section 4. Cardiac arrest in special circumstances. Resuscitation. 2015;95:148-201.

9. Ehrlich MP, McCullough JN, Zhang N, Weisz DJ, Juvonen T, Bodian CA, et al. Effect of hypothermia on cerebral blood flow and metabolism in the pig. Ann Thorac Surg. 2002;73(1):191-7.

10. McCullough JN, Zhang N, Reich DL, Juvonen TS, Klein JJ, Spielvogel D, et al. Cerebral metabolic suppression during hypothermic circulatory arrest in humans. Ann Thorac Surg. 1999:67(6):1895-9. discussion 919-21

11. Lavonas EJ, Drennan IR, Gabrielli A, Heffner AC, Hoyte CO, Orkin AM, et al. Part 10: Special Circumstances of Resuscitation: 2015 American Heart Association Guidelines Update for Cardiopulmonary Resuscitation and Emergency Cardiovascular Care. Circulation. 2015;132(18 Suppl 2):S501-18.

12. Pasquier M, Hugli O, Paal P, Darocha T, Blancher M, Husby P, et al. Hypothermia outcome prediction after extracorporeal life support for hypothermic cardiac arrest patients: The HOPE score. Resuscitation. 2018; 126:58-64.

13. Pasquier M, Rousson V, Darocha T, Bouzat P, Kosinski S, Sawamoto K, et al. Hypothermia outcome prediction after extracorporeal life support for hypothermic cardiac arrest patients: An external validation of the HOPE score. Resuscitation. 2019;139:321-8.

14. Saczkowski RS, Brown DJA, Abu-Laban RB, Fradet G, Schulze CJ, Kuzak ND. Prediction and risk stratification of survival in accidental hypothermia requiring extracorporeal life support: An individual patient data metaanalysis. Resuscitation. 2018;127:51-7.

\section{Publisher's Note}

Springer Nature remains neutral with regard to jurisdictional claims in published maps and institutional affiliations.

Ready to submit your research? Choose BMC and benefit from:

- fast, convenient online submission

- thorough peer review by experienced researchers in your field

- rapid publication on acceptance

- support for research data, including large and complex data types

- gold Open Access which fosters wider collaboration and increased citations

- maximum visibility for your research: over $100 \mathrm{M}$ website views per year

At $\mathrm{BMC}$, research is always in progress.

Learn more biomedcentral.com/submissions 